ISSN electrónico: 2172-9077

DOI: https://doi.org/10.14201/fjc2016138598

\title{
APUNTES TEÓRICO-METODOLÓGICOS PARA UN ESTUDIO DE LA MENSAJERÍA INSTANTÁNEA DESDE LAS CIENCIAS SOCIALES Y LAS HUMANIDADES
}

\section{Notes for Methodological Study of Instant Messaging from Social Sciences and Humanities}

Dra. Rosalba MANCINAS-CHÁVEZ

Profesora de la Universidad de Sevilla. España

E-mail: rmancinas@,us.es

(iD) http://orcid.org/0000-0002-4218-2338

\author{
Dr. Ramón REIG \\ Catedrático en la Universidad de Sevilla. España \\ E-mail: ramonreig@us.es \\ (iD) http://orcid.org/0000-0003-2663-4223
}

Fecha de recepción del artículo: 06/10/2016

Fecha de aceptación definitiva: 26/10/2016

\begin{abstract}
RESUMEN
Este artículo defiende la necesidad de la transversalidad cuando se aborda metodológicamente desde las ciencias sociales y las humanidades la cuestión de la mensajería instantánea a partir del teléfono móvil como herramienta de comunicación. Ello nos conduce al enfoque estructural que, a su vez, exige acudir a saberes auxiliares como la psicología o la historia sin perder de vista que se trata de un texto construido desde la comunicación y el periodismo. Pretendemos huir de los enfoques funcionales para pensar el significado del móvil como objeto comunicacional paliativo de la soledad humana, por ejemplo. Entendemos que una parte de la llamada investigación aplicada como algo útil a la sociedad, debe tomar ese camino si desde las ciencias sociales y las humanidades trabajamos. Esta cuestión alcanza aún mayor importancia cuando España se ha colocado al frente de los principales países europeos en lo que se refiere al uso del sistema de las redes sociales de comunicación con aplicaciones de software como Whats App.
\end{abstract}

Palabras clave: Enfoque structural; comunicación; psicosociología; mensajería instantánea.

\begin{abstract}
This article defends the need for transversality when methodologically addressing instant messaging via cellphones as a tool of communication from the point of view of social sciences and humanities. This leads us to the structural approach, which requires supplementary knowledge in fields such as Psychology or History, without losing sight that our study is composed in the areas of Communications and Journalism. We intend to avoid the functional approaches to think about the meaning of mobile phones as a communicative and palliative object of human loneliness. We believe that a part of the so-called applied research, in being useful to society, must take that path if we work as social science or humanities researchers. This issue gains even greater importance knowing that Spain is at the top of leading European countries in terms of the use of social networking systems of communication with software applications such as Whats $A p p$.
\end{abstract}

Key words: Structural approach; communication; psychosociology; instant messaging. 


\section{INTRODUCCIÓN}

La mensajería instantánea ha pasado a formar parte inevitable de los hábitos de una gran mayoría de la población (Carrión, 2016). Entendemos mensajería instantánea como el intercambio de mensajes de manera sincrónica donde la comunicación se da en tiempo real, los mensajes son escritos y leídos al mismo tiempo, a pesar de la distancia que media entre los usuarios (Torres Fernández y Pérez Sánchez, 2013). El uso de la mensajería instantánea requiere de aplicaciones de software especializado en ordenadores o dispositivos móviles.

El presente trabajo surge a partir de la honda preocupación que, como investigadores y docentes, observamos en torno a la dependencia de Internet en general y de la mensajería instantánea en particular. Nuestra experiencia deviene de la observación de la sociedad y el contacto habitual con estudiantes universitarios. Creemos que esta dependencia está ya afectando al rendimiento académico y a la comprensión de lo que se explica. Por tanto, consideramos necesario comenzar por trazar unas líneas teórico-metodológicas mediante las cuales acometer en futuro inmediato una investigación profunda sobre el particular, un trabajo que vaya más allá de las líneas tecnicistas y de mercadotecnia tan al uso en nuestros días.

Francis Fukuyama (2000) llegó a reconsiderar sus tesis sobre «el fin de la Historia» al observar una serie de fenómenos nuevos, algo que celebramos, puesto que su fin de la historia sigue siendo, a nuestros ojos, una teoría descabellada por no decir ingenua. Uno de los factores que Fukuyama contempló como novedoso (y peligroso) era el cibernético. Nosotros creemos que uno de los retos de los seres humanos en el siglo XXI es que sea ese ser quien controle a lo ciber y no al revés. No nos referimos solo a esa posible implantación de la Inteligencia Artificial (IA) por encima de la de sus creadores, como defiende Stephen Hawkins (2014), sino, para empezar, al «control» que las herramientas digitales (como la mensajería instantánea) ejerce sobre el usuario, revertiendo tal vez el asunto: el usuario no es tal, sino que es usado por la herramienta.

Pretendemos concretar un esbozo de algunas consideraciones teóricas con relación al estudio de los usos y efectos de la mensajería instantánea desde la perspectiva de las ciencias sociales y humanidades. Para ello, consideramos esencial el estudio desde la perspectiva de las humanidades de los nuevos objetos electrónicos, incluyendo nuevas narrativas y formatos, y su significado cultural. Asimismo, es interesante el análisis desde la perspectiva de las humanidades de los efectos de Internet en el plano de la cultura. Una investigación de la mensajería instantánea desde el ámbito complejo que proponemos debería plantearse los siguientes objetivos:

1. Aportar una visión estructural y, por ello, interdisciplinaria, constructiva y útil para quien acceda a nuestro trabajo, sobre un problema que está tomando cauces preocupantes.

2. Llevar a cabo una labor de síntesis y sincrónica entre perspectiva histórica, contexto y actividad empírica en torno al tema que nos ocupa.

3. Acercarnos al mayor o menor grado de gravedad y posible repercusión social que, con vistas al futuro, el problema encierre.

4. Indagar en otros momentos de la Historia que nos ayuden a explicarnos el asunto en cuestión.

5. Si es preciso, alertar a los agentes sociales en particular y a toda la sociedad sobre los peligros que para su desarrollo cognitivo, mercantil y democrático puede acarrear una «adicción» a algunas herramientas derivadas de la «revolución digital». 
6. Demostrar que la investigación aplicada no debe referirse solo a las llamadas ciencias puras, sino que también son tremendamente válidas las consideraciones y conclusiones procedentes de las ciencias humanas y sociales.

\section{APROXIMACIÓN A LA FUNDAMENTACIÓN TEÓRICO-METODOLÓGICA PARA PENSAR EL SIGNIFICADO DEL MÓVIL Y SU MENSAJERÍA INSTANTÁNEA}

Lo primero es el problema, afirmó Karl Popper (2008). Pues bien, el hecho de que España sea el país europeo que más use el móvil como plataforma de mensajería instantánea (Carrión, 2016) con el riesgo que conlleva la llamada lectura digital -donde el fenómeno se inserta y al que nos referiremos después- supone ya un problema sobre el que no hay que dramatizar ni exagerar, pero sí tenerlo en seria consideración. Paula Carrión (2016) informa:

Los españoles son los europeos que más usan mensajería instantánea a
diario a través de aplicaciones como WhatsApp o Telegram según se re-
fleja en el Eurobarómetro sobre comunicación digital realizado por TNS.
Por este motivo los españoles son, a su vez los ciudadanos de la Unión
Europea que menos mensajes (SMS) mandan en su día a día, tal y como
se desprende del mismo estudio.

El cambio de hábitos es una realidad, la respuesta inmediata que supone la mensajería instantánea forja una nueva forma de comprender la comunicación y unas nuevas expectativas en torno al intercambio entre emisor y receptor. El control que el emisor quiere tener de la recepción de su mensaje y de la respuesta es una parte interesante que las aplicaciones de mensajería instantánea ofrecen por encima del clásico servicio de SMS. Carrión (2016) continúa aportando algunos datos a tener en cuenta:

Según la encuesta realizada en octubre de 2015 un 57\% de los españoles usa a diario aplicaciones de mensajería, seguido por holandeses e italianos con un $50 \%$. Solo uno de cada tres españoles no usa nunca este tipo de apps, el porcentaje más bajo de toda la Unión. En el otro extremo se encuentran países como República Checa o Grecia donde solo el 11\% y el 16\% respectivamente utilizan a diario este tipo de servicios de comunicación.

El hecho de que en España se utilice tanto plataformas como WhatsApp o Telegram lleva ligado el poco uso de los tradicionales mensajes o SMS. Los datos del Eurobarómetro confirman que solo un $6 \%$ de los españoles manda mensajes de texto a diario, mientras que un $62 \%$ asegura no enviar nunca ninguno. El número de españoles que usa SMS es siete veces menor que la media europea que se sitúa en el $45 \%$. Los europeos que más envían SMS a diario son los irlandeses: 3 de cada cuatro encuestados afirman hacerlo a diario.

El Grupo de Investigación en Estructura, Historia y Contenidos de la Comunicación (GREHCCO) de la Universidad de Sevilla, al que pertenecemos los firmantes de este texto, comenzó a indagar en el significado científico-comunicacional del móvil en los años noventa, pero la aparición de la mensajería instantánea gratuita nos ha obligado a volver sobre ella con mayor atención en nuestros días.

La psiquiatra terapeuta y profesora de Conducta Humana en la Facultad de Medicina de Sevilla, María Dolores Otero Castelló (2002), colaboradora de nuestro grupo, publicó un artículo sobre her- 
menéutica aplicada a la significación psicosocial del móvil en el que llegó a las siguientes conclusiones y consideraciones, expresadas en una primera parte en un tono indirecto, con sentido del humor, como ella misma justifica:

Los cambios psicológicos, sociales, psicosociales y culturales más significativos que podemos atribuir a esta tecnología (y aquí me permito abordarlo con cierto sentido del humor) o que puede vislumbrarse que producirán serían:

- Cambio en el mobiliario urbano. Podremos contemplar en nuestras ciudades esculturas vivientes, quietas, aisladas, deambulando abstraídas, circunspectas o sonrientes, chillonas o silentes.

- Aumento de las posibilidades de autoagresión, por olvidarse o perder el nuevo y valioso objeto; no solo por la torpeza o el descalabro económico que supone sino por la dependencia que vamos creando de la agenda o del número correspondiente y proporcionado a los elegidos «¿Cómo funcionaré sin MI móvil?» Como consecuencia, más estrés.

- Problemas de reciclaje. Salen modelos nuevos o, como todo elemento «caducable», deja de funcionar; pero sobre todo hay que seguir consumiendo.

- Gracias al móvil podremos distinguir mejor los sujetos respetuosos de los agresivos sociales (creo que no necesita aclaración).

- Aporta un nuevo elemento para la diferenciación/identificación y el estatus.

Otero Castelló (2002), en un momento en el que el uso del móvil se expandía a gran velocidad, pero no era ni siquiera previsible que llegara a convertirse en poco más de una década en lo que tenemos hoy, cambia el tono para continuar enunciando las posibles transformaciones de la conducta psicosocial derivadas de esta tecnología:

- Permite afrontar un mayor número de experiencias que comportan, de forma absoluta o relativa, factores de riesgo, a un más amplio grupo de población, disminuyendo significativamente e incluso eliminando las consecuencias lesivas que puede ocasionar la aparición de determinadas eventualidades.

En este aspecto YA ES IMPAGABLE, y justifica por sí solo la existencia y aceptación del móvil, su influencia decisiva en la feliz resolución de situaciones críticas (catástrofes, secuestros, etc.). Rompe el aislamiento forzoso, elimina el «silencio» de la imposibilidad de contacto y por tanto disminuye o disuelve la ANGUSTIA.

Por esta función, inherente a sus características, el buen uso del móvil influye e influirá significativamente en las vivencias de SEGURIDAD Y LIBERTAD.

- Ya las nuevas generaciones de móviles permiten el acceso a Internet, por tanto a mayor información en cualquier momento o lugar, lo que en sentido positivo se traduce en una mayor OPERATIVIDAD Y LIBERTAD. 
- Y por último introduce nuevos elementos de interactuación y comunicación, modificándola ¿cuantitativa o cualitativamente?.

Estas serían unas afirmaciones interesantes a tomar en cuenta en nuestro enfoque metodológico ¿ha disminuido o diluido la angustia el uso del móvil tal y como lo preveía Otero Castelló? ¿Propicia realmente más seguridad y libertad? Es quizá uno de los grandes interrogantes que dan sentido al planteamiento desde un enfoque estructural, la libertad o esclavitud que supone la mensajería instantánea.

Volviendo a nuestro cauce metodológico, el Premio Nobel Konrad Lorenz (1995) hablaba de la conveniencia de llevar a cabo un ejercicio de epistemología comparada. Las corrientes del llamado pensamiento complejo (Morin) van en una dirección similar: no es posible explicarse o intentar explicarse correctamente un acontecimiento sin una visión estructural de los múltiples elementos en liza. «El término "complejo" designa hoy una comprensión del mundo como entidad donde todo se encuentra entrelazado, como en un tejido compuesto de finos hilos». El mismo Morin escribió (en Barberousse, 2008):

Nunca pude, a lo largo de toda mi vida, resignarme al saber parcelado, nunca pude aislar a un objeto de estudio de su contexto, de sus antecedentes, de su devenir. He aspirado siempre a un pensamiento multidimensional. Nunca he podido eliminar la contradicción interior. Siempre he sentido que las verdades profundas, antagonistas las unas de las otras, eran para mí complementarias, sin dejar de ser antagonistas. Nunca he querido reducir a la fuerza la incertidumbre y la ambigüedad.

Nuestra metodología se basa, por tanto, en las ciencias de la complejidad que aparecen cuando se trata de investigaciones que en diversos campos hacen avanzar el conocimiento científico al introducir una comprensión del mundo como sistema entrelazado. He aquí el vacío que observamos en la actualidad en el conocimiento científico y en la sociedad en general que incluso, en nuestra opinión, se refleja en los estudiantes cuando los distintos informes PISA nos advierten de que los jóvenes alumnos españoles no son capaces de llevar bien a término un análisis donde se interrelacionen debidamente distintos elementos.

Podríamos extendernos mucho en este tipo de metodología, pero ya lo hemos hecho en estudios anteriores (Reig, 2010, Reig, 2011, Reig y Mancinas, 2013) por lo que creemos que con las ideas expuestas es suficiente, si bien es necesario matizar que el enfoque de la complejidad puede alcanzar mayores o menores grados de articulación de elementos. En este caso, entran en escena varias epistemologías relacionadas con las siguientes áreas de conocimiento:

- Historia.

- Filosofía.

- Comunicación.

- Psicosociología.

La fundamentación de nuestra metodología se la debemos además a dos estudiosos fundamentalmente. En primer lugar, al teórico de la comunicación e impulsor del Análisis Crítico del Discurso

\footnotetext{
${ }^{1}$ Las palabras en caja alta son de la autora. 
(ACD) Teun A. Van Dijk para quien sin contexto no hay texto (Van Dijk, 1999). En efecto, sin contexto tanto el móvil como su mensajería instantánea se convierten en simples artilugios tecnológicos. Sin embargo, ambos tienen un sentido contextual como hemos visto y como comprobaremos más adelante.

El otro autor es el sociobiólogo Edward Wilson que, a pesar de su condición de biólogo, considera esencial la participación de las humanidades para la comprensión sincrónica de los acontecimientos (Wilson, 2014). Para Wilson, es cierto que la ciencia y las humanidades son fundamentalmente distintas la una de la otra en lo que afirman y en lo que hacen. Pero se complementan la una a la otra en origen, y surgen de los mismos procesos creativos en el cerebro humano. Si el poder heurístico y analítico de la ciencia se puede unir a la creatividad introspectiva de las humanidades, la existencia humana se elevará a un significado infinitamente más productivo e interesante.

\section{El POLÉMICO CONTEXTO DERIVADO DE LA MUNDIALIZACIÓN, OTRO PILAR TEÓRICO Y OTRO HECHO PARA UNA METODOLOGÍA ESTRUCTURAL}

El problema del móvil viene derivado de su pertenencia a los fenómenos devenidos desde la lectura digital, sin embargo, para entenderlo, es necesario considerar también el contexto complejo en el que tanto ésta como una de sus manifestaciones y/o aplicaciones del móvil -la mensajería instantánea- están inmersas: la mundialización. Primero, la tecnología en red nos ha llevado a la hiperinformación y ésta a la infoxicación.

La mundialización es la suprema expresión de la dinámica mercantil, es el contexto mundial más amplio donde todo está contenido (nos referimos al mundo más avanzado, el otro sufre o goza de su presencia). La concentración mercantil y a la vez la diversificación del capital son elementos clave de ese contexto (Reig, 2011). Del macro-contexto mundialización se deriva la hiperinformación o infobesidad y de ahí la infoxicación, todo ello en el marco de la lectura digital. Según Pérez-Lanzac (2013) la lectura digital es un ejercicio de dispersión que se realiza saltando de una pantalla a otra. El uso de vínculos e hipervínculos lleva al lector a un vídeo, un mapa, un informe o una página de publicidad. Es cierto que los lectores actuales tienen mucha más información a su alcance y la cantidad de lectura es mayor, pero el nivel de concentración es menor:

\footnotetext{
Según los expertos, hay un nuevo fenómeno que afecta cada vez a más personas: la atención parcial continua. Es lo que sucede cuando pasamos mucho tiempo ante una pantalla, que estamos pendientes de muchas cosas, pero sin llegar a solidificar nada (Pérez-Lanzac, 2013).
}

Si profundizamos más en el tema desde una perspectiva neorocomunicacional encontramos descubrimientos muy seductores:

Los nativos digitales suelen almacenar links en lugar de contenido, a veces sin razonar, de esta forma, el instinto natural del cerebro les lleva a cometer actos violentos en algunos juegos de combate sin cuestionarse.

Los nativos digitales tienen memoria superficial, mientras que aquellos que leen tienen un acercamiento lineal que les permite retener la información a través de un proceso cognitivo desarrollado en la corteza prefrontal (Prensa Libre.com, 2016). 
Siguiendo con el enfoque neurocomunicacional -y para situar la cita anterior en un significado más amplio- se ha estudiado cómo funciona el cerebro de los usuarios de la lectura digital que hoy se ejerce en muy alta medida a través de los Smartphone. La Agencia France Presse (AFP) (2016) se hacía eco de lo más esencial del tema:

Entre los 13 y los 19 años de edad, la necesidad de rebelarse puede rivalizar con el deseo de amoldarse o de adoptar nuevas tendencias que horrorizan a los padres, fascinan a los sociólogos y hacen las delicias de quienes buscan rentabilizar las modas pasajeras. Durante millones de años el cerebro humano se ha adaptado al ritmo de la escritura, la lectura y más recientemente, a la comunicación digital. Ahora la adaptación depende de la velocidad. Las cortezas motor y premotora del cerebro dirigen nuestras acciones; los niños que han crecido en la era digital son excepcionalmente hábiles y rápidos, gracias a los videojuegos basados en recompensas, a los que están acostumbrados. Este principio de recompensa libera dopamina, estimulante natural que se encuentra en la corteza prefrontal y en el sistema límbico. Los nativos digitales suelen almacenar links en lugar de contenido, a veces sin razonar, de esta forma, el instinto natural del cerebro les lleva a cometer actos violentos en algunos juegos de combate sin cuestionarse. Los nativos digitales tienen memoria superficial, mientras que aquellos que leen tienen un acercamiento linear que les permite retener la información a través de un proceso cognitivo desarrollado en la corteza prefrontal.

En definitiva, se deduce que nuevos elementos llevan ya tiempo actuando en la evolución humana a causa de la lectura digital y de su herramienta: el móvil o celular, y también deducimos que demonizar lectura digital y herramienta sería algo carente de rigor e incluso una dinámica propia de la resistencia al cambio de determinados cerebros sean de investigadores o de ciudadanos comunes. Lo que procede ahora es investigar a fondo la nueva circunstancia histórica que es lo que proponemos, investigarlo desde una perspectiva totalizadora y no parcial o técnica donde todo o casi todo se reduce a porcentajes y cantidades.

La lectura digital es el efecto cultural del vértigo vital originado por la mundialización. Dicho vértigo condujo al viñetista El Roto (2014) a publicar un dibujo en el que un individuo bien vestido que sostenía en una de sus manos unos papeles al tiempo que hablaba por teléfono y miraba la pantalla de su ordenador portátil, decía: «Gracias a las nuevas tecnologías me informo al segundo y lo olvido al instante».

La frase anterior encierra, entre otros significados, una confianza absoluta en las nuevas herramientas tecnológicas como transmisoras de información, pero también una crítica a la saturación. Ya veremos más adelante el tema de la saturación, pero antes abordaremos el de la confianza, que es muy marcada en las nuevas generaciones de nativos digitales quienes, teléfono inteligente en mano, creen poseer el conocimiento, acaso olvidándose de que el conocimiento no son datos más o menos aislados, sino metodologías hermenéuticas a veces muy complejas que deben abordarse con la ayuda del profesor. Estamos pensando cuando abordamos esta cuestión en el filósofo Michel Serres (2014) quien, posiblemente víctima de un estado de «éxtasis cibernético» (Reig, 2001), estima que los alumnos poco menos que se burlan de sus profesores en clase porque no los necesitan al atesorar en sus celulares y computadoras lo que les están diciendo. Algunas ideas de Serres son: 
- El profesor, antes, pedía silencio y lo obtenía, gracias a su cátedra.

- Explicaba lo que está en los libros.

- Ahora ya no obtiene silencio, los alumnos «parlotean». ¿Por qué?

- Porque el saber que anuncia el profesor ya «lo tiene todo el mundo».

- Por tanto, es necesario crear para que profesores y alumnos no estén incomunicados.

- «Ya no hay maestros en el aula, todo está lleno de profesores». Una de sus herramientas es Wikipedia.

Serres tiene buena parte de razón: hay que crear, el profesor tiene un enemigo implacable: la Red. Pero negar -aunque sea metafóricamente- la existencia de maestros en el aula para colocar a todos a la misma altura intelectual y, para colmo, señalar a Wikipedia como una fuente de información académica, es ya un atrevimiento muy considerable. Serres ha sido poseído y se niega a sí mismo, aunque suponemos que él se considerará una de las excepciones a la posible regla de los profesores desfasados.

Como se indicó antes, se relaciona estrechamente la lectura digital con conceptos como infobesidad, hiperinformación, que a su vez llevan a la infoxicación (Cornellá, 2004). Y el móvil y sus aplicaciones están en el centro de la situación.

La «infobesidad» se manifiesta con algunos signos inequívocos. Estrés, angustia, ansiedad, frustración ante el exceso de información por el correo electrónico y la actualización de redes sociales. Quien padece este trastorno se ve abocado a un estado de ansiedad por estar continuamente abriendo los distintos perfiles para actualizar información, contestar, interactuar, saber si han respondido, etc. Esta obsesión acaba desembocando en un caos de estrés y frustración que impide gestionar la información con normalidad.

En los primeros años del siglo XXI el problema se centraba en la gestión del correo electrónico, desde hace un par de años, el uso de mensajería instantánea utilizando herramientas como el Whats App Messenger hacía furor entre gran parte de la población española, sobre todo joven, y superaba con creces al correo electrónico, como indicaba el diario 20 Minutos el 22 de abril de 2014:

El uso de mensajería instantánea supera al correo electrónico por primera vez. Así lo indica la última oleada del Estudio General de Medios (EGM), correspondiente a los meses de febrero y marzo de 2014. El $82,7 \%$ de los internautas diarios recurre a apps como Whats App o Telegram, frente al 75,5\% en la anterior oleada (octubre-noviembre de 2013). El uso del e-mail, por su parte, bajó del 74,1\% hasta el 69,5\% en febreromarzo. También entre las dos últimas oleadas ha bajado el uso de redes sociales, el consumo de series y películas en Internet y la compartición de archivos.

Por su parte, El País iba más allá de los datos españoles y llegaba hasta esos países llamados emergentes como India, Rusia, Brasil y México:

«Muchísimas gracias a todos», así comienza el mensaje de Jan Koum, fundador y consejero delegado de WhatsApp para anunciar que la aplicación de mensajería supera los 500 millones de usuarios activos mensuales. La última vez que desvelaron sus cifras fue el 19 de diciembre, entonces rebasaron la frontera de los 400. Es decir, en cinco meses, 100 millones adicionales. India, Rusia, Brasil y México son los lugares donde 
más han crecido. En Brasil superan 45 millones. España, uno de los lugares donde el uso es más activo, ya tiene 25 millones. En todo el mundo se comparten, a diario, 700 millones de fotos y más de 100 millones de vídeos. WhatsApp insiste en que su medición dista de la competencia en la consideración de los usuarios. En lugar de contar los registros, solo cuentan a aquellos que han usado su servicio al menos durante el último mes. La aplicación que compró Facebook en febrero mantiene su intención de añadir mejoras. Durante el MWC de Barcelona indicaron que trabajan para añadir llamadas entre móviles. Quizá ese sea el motivo de la despedida del mensaje por parte del consejero delegado: «Podríamos seguir, pero, ahora mismo, es mejor que volvamos a trabajar duro. Esto es WhatsApp y no hemos hecho más que empezar».

En el diario La Vanguardia, se publicaba una breve, pero interesante, noticia con relación al crecimiento de la infobesidad en España, aportando algunos datos interesantes:

La obsesión por mirar el correo electrónico atrapa al 56\% de los usuarios de correo electrónico, quienes emplean como mínimo 2 horas al día a administrar el email

$[\ldots]$

Thierry Venin, investigador del Centro Nacional de Investigación Científica (CNRS), indicaba que «la urgencia sucede a la urgencia». Afirmaba Venin: «Tan pronto recibimos un email hay que responderlo; caso contrario, el remitente nos llama para preguntarnos si lo recibimos. Además, cuando tenemos un minuto libre vamos al buzón de correo para ver si hay algo nuevo. Es como una adicción».

Por otro lado, Hiperinformación es un término que se maneja desde el pasado siglo XX, cuando empezó a preocupar la diferencia entre información y conocimiento. Por un lado la información empezó a circular a un ritmo mucho más elevado a la demanda y a la posibilidad de consumo informativo de los usuarios. Los primeros en hablar de hiperinformación fueron los informáticos y lo hacían para definir los modelos, arquitecturas e interfaces que soportan la integración e interactividad de distintos tipos de datos (Cortés Amador, 1993). De alguna es una fase de exceso de información que hunde sus raíces más profundas en la invención de la imprenta y da un gran paso cuando la voz humana consiguió propagarse a través del espectro electrónico.

Ignacio Ramonet (1998) trae el término al ámbito de la comunicación y lo interpreta como una forma de censura, habla de sobreabundancia informativa, de exceso de información. En todo caso nos referimos y entendemos el término hiperinformación como el fenómeno actual en el que los seres humanos se ven desbordados por tal cantidad de información que difícilmente pueden centrarse en algo concreto. Directamente relacionado con el problema de la mensajería instantánea, que representa una forma muy atractiva de estar hipercomunicado, siempre disponible, siempre on. Con este término enlazamos con el siguiente concepto, infoxicación, la forma en que Alfons Cornellá (2014) denomina a la sobredosis de información que debemos manejar cada día:

La infoxicación es el exceso de información. Es, pues, lo mismo que el information overload. Es estar siempre «on», recibir centenares de informaciones cada día, a las que no puedes dedicar tiempo. Es no poder profundizar en nada, y saltar de una cosa a la otra. Es el «working inte- 
rruptus». Es el resultado de un mundo en donde se prima la exhaustividad («todo sobre») frente a la relevancia («lo más importante»).

Es importante mencionar que Alfons Cornellá procede del ámbito de las ciencias, es Físico de formación, ha fundado una consultora para asesorar a las empresas en la gestión de la información. Según él, la infoxicación es una especie de intoxicación informacional que padece nuestro cerebro por la gran cantidad de datos que percibe al día (Cornellá, 2004).

Una vez más se hace patente el estudio que planteamos desde un ámbito metodológico interdisciplinario y transversal, las matemáticas, la física y la informática están fuertemente relacionadas con el objeto de investigación que planteamos.

La complejidad de la situación que nos obliga a entrar metodológicamente en el estudio del fenómeno móvil-principales aplicaciones desde las ciencias sociales y las humanidades es, por tanto, aún mayor cuando hemos pasado desde el móvil vamos a llamarle tradicional a tener el mundo en nuestras manos gracias al Smartphone que, además de todo lo dicho hasta aquí, se caracteriza por ir dejando una huella detalladísima y pormenorizada de nuestra presencia, existencia y rastro en el mundo (desde estar en casa hasta acudir a una manifestación de protesta). En YouTube hay un texto que nos documenta en menos de diez minutos sobre el asunto (Peirano, 2015). La periodista Marta Peirano da cuenta de cómo nuestros móviles son una especie de chips que nos tiene siempre localizados, aunque no los estemos usando, basta con llevarlos encendidos. Este hecho conlleva dos efectos: el control desde el poder y la utilización del ser humano para fines comerciales aún sin su permiso.

Desde el enfoque estructural complejo no podemos dejar de lado los fines mercantiles que se esconden tras ese servicio gratuito que nos ofrecen las aplicaciones para el intercambio de mensajería instantánea. En agosto de 2016 se hizo pública la intención de Facebook, la empresa con mayor cantidad de usuarios en el mundo, de intercambiar la información de los usuarios registrados en WhatsApp, el servicio de mensajería instantánea de su propiedad desde 2014 (El País, 26 de agosto de 2016). Es, desde luego, un negocio redondo, nunca antes fue tan clara la afirmación de Dallas W. Smythe, «la audiencia es la mercancía».

\section{CONCLUSIÓN Y PROPUESTAS}

Estimamos muy conveniente detenerse desde las ciencias sociales y las humanidades en el significado que los móviles y su aplicación principal -la mensajería instantánea- posee para el transcurrir de nuestras vidas. Dicho significado debe demostrarse mediante una metodología estructural que unifique diversas capas del saber y tenga en cuenta el contexto socioeconómico por el que atravesamos. Por tanto, la escuela que conocemos como Economía Política de la Información, la Comunicación y la Cultura tiene mucho protagonismo en nuestro enfoque.

Hay que desarrollar un acercamiento interdisciplinario al tema desde parcelas humanísticas y de ciencias sociales puesto que la diversidad formativa de nuestro grupo de investigación lo permite.

En una primera instancia abordaríamos las vertientes contextuales. Nos referimos con ello a la elaboración del Estado de la Cuestión, una introducción al trabajo, el planteamiento de unas hipótesis que nos sirvan de rumbo, desarrollo de la metodología y los aspectos teóricos y de contexto a tener en cuenta, como los fundamentos históricos de los impactos psicosociales tecnológicos y el significado de la mensajería instantánea en el contexto de la mundialización de la comunicación (Mattelart, 1998).

Por otro lado, en segunda instancia se abordarán los resultados psicosociales, la perspectiva psicosocial que utilizamos para el desarrollo del trabajo, la metodología aplicada, considerando una selec- 
ción de la muestra en segmentos sociales de usuarios de las tecnologías de la información objeto del estudio y los resultados divididos en las siguientes áreas:

- Principales impactos psicosociales de la mensajería instantánea.

- Impactos psíquicos.

- Impactos sociales.

- Impactos psicosociales.

La elaboración de las conclusiones nos llevará a considerar el significado contextual del tema desde las humanidades y las ciencias sociales. Más en concreto, la metodología estructural y compleja que proponemos se deriva de la siguiente dinámica de hipótesis y hechos:

- La aparición y el avance de las tecnologías siempre han supuesto un cambio sustancial en el proceder de la especie humana, desde la revolución agrícola hasta las revoluciones tecnológicas pasando por las revoluciones industriales.

- Estas últimas, las revoluciones industriales que se inician sobre todo en el siglo XIX, determinan el mundo del siglo XXI porque, entre sus logros, se encuentra la producción en serie que conduce necesariamente a la sociedad de consumo, estimulada por la publicidad y otras formas de creación artificial de necesidades. La ecuación clásica que había guiado a la Humanidad desde sus orígenes:

Necesidad-Producción-Consumo, pasa a convertirse en: Producción-Creación de la necesidad-Consumo.

- Las revoluciones tecnológicas de finales del siglo XX y del siglo XXI aumentan ese consumo y esa producción en serie, así como los instrumentos que los seres humanos utilizan para intercomunicarse. La diferencia ahora es que la intercomunicación se vuelve individual totalmente, pero también que tal individualidad posee, al mismo tiempo, características alienadoras que convierten al sujeto en una masa dispersa que no deja de serlo ni cuando se une físicamente.

- Todo lo anterior conlleva cambios sociales e individuales, cambios cerebrales, cambios conductuales, pero no necesariamente un aumento del conocimiento, aunque sí de la información. El sujeto sabe más de lo que sucede a su alrededor -o puede saberlo- pero no lo comprende, no lo aprehende mejor y sin asimilación articulada de los elementos no hay comprensión real del acontecimiento.

Lo que se presenta entonces como de imprescindible estudio es si estamos ante un nuevo sujeto más y mejor formado, ante un sujeto híbrido o ante el «sabio ignorante» (Sans, 1763) ${ }^{2}$.

Si esta situación se produce, ¿habría reacción del individuo hacia el conocimiento o entraríamos en una nueva etapa histórica similar al mundo feliz, es decir, a los principios neoliberales de distraer y evadir a los seres humanos para que sean felices desde el punto de vista de dicha ideología? (Escalante

\footnotetext{
2 Aunque encontramos en Sans una referencia ancestral con esa expresión, en nuestros días la solemos tomar de un hecho: Ortega y Gasset publicó hacia 1930 su conocido libro La rebelión de las masas. Uno de sus capítulos se denomina «La barbarie del 'especialismo'», donde anunció la invasión del mundo por una nueva especie: los sabios ignorantes, es decir, los que sabían mucho de poco e ignoraban el sentido y significado del gran contexto en el que habitaban.
} 
Gonzalbo, 2016). ¿Se darían reacciones minoritarias e individuales contra esta especie de totalitarismo, unas reacciones donde los aspectos genéticos y culturales - por este orden- tendrían mucho que decir? Entonces, y para terminar, ¿Qué campos principales del saber entrarían en nuestra metodología?

- Historia y psicohistoria.

- Antropología.

- Genética y neurociencia.

- Etología.

- Psicología Social.

- Contexto mundial socioeconómico y mediático.

¿Cómo se articularían? La Historia, la Psicohistoria y la Antropología nos hablarían sobre los antecedentes del fenómeno y sobre «cómo las cosas han llegado a ser lo que son» (Boas, en Valdés Gázquez, 2006). La misión de la genética y la neurociencia es informarnos y formarnos sobre el papel que lo innato juega en esta nueva dinámica tecnosocial y cómo influye tal dinámica en los cambios cerebrales mientras que la Etología y la Psicología Social -en conexión con las anteriores- tienen la obligación de estudiar los comportamientos de los sujetos, todo ello desenvolviéndose en un entorno contextual mundial que influye en el individuo y a su vez es influido por él. En realidad, se trata de un hecho global que despierta varios elementos quienes a su vez conforman el hecho.

\section{REFERENCIAS}

20 Minutos (2014, 22 de abril). El uso de mensajería instantánea supera al correo electrónico por primera vez. Recuperado de: http://www.20minutos.es/noticia/2119047/0/mensajeriainstantanea/supera-uso/correo-electronico/\#xtor=AD-15\&xts=467263\#xtor=AD$15 \& x \operatorname{se}=467263$.

AFP. (2016). La lectura digital: el cerebro, Redacción/AFP, 24 de Febrero de 2016, Recuperado de: http://www.prensalibre.com/internacional/como-funciona-el-cerebro-de-los-nativos-digitales.

Barberousse, P. (2008). Fundamentos teóricos del pensamiento complejo de Edgar Morin. Revista Electrónica Educare, 12(2). Recuperado de: http://www.redalyc.org/articulo.oa?id=194114586009.

Carrión, P. (2016). Whatsapp, un asunto español. En Kantar España Insights. Recuperado de: http://es.kantar.com/tech/m\%C3\%B3vil/2016/junio-2016-datos-sobre-el-uso-de-lamensajer $\% \mathrm{C} 3 \% \mathrm{ADa}$-instant $\% \mathrm{C} 3 \% \mathrm{~A} 1$ nea-en-europa/

Cornellá, A. (2004). Infoxicación. Buscando un orden en la información. Barcelona: Libros de infonomía.

Cornellá, A. (s.f.) ¿Qué es la infoxicación? Recuperado de: http://alfonscornella.com/thought/infoxicacion/

Cortés Amador, C. (1993). Redes de conocimiento vivo e hiperinformación. Ingeniería e investigación, 30 , 79-86. Recuperado

http://www.docentes.unal.edu.co/cacortesa/docs/Redes $\% 20 \mathrm{de} \% 20$ conocimiento $\% 20 \mathrm{vivo} \% 20$ e\%20hiper\%20informacion.pdf.

El País (2016, 26 de agosto). Facebook tendrá acceso al número de teléfono de los s usuarios de WhatsApp. Recuperado de: http://tecnologia.elpais.com/tecnologia/2016/08/25/actualidad/1472130602996229. html?rel $=$ mas 
El País (2014, 22 de abril). WhatsApp supera 500 millones de usuarios. Recuperado de: http://tecnologia.elpais.com/tecnologia/2014/04/22/actualidad/1398191305 540693. html.

El Roto (2014). Viñeta sobre lectura digital: http://www.bernatllopis.es/2014 0201 archive.html

Escalante Gonzalbo, F. (2016). Historia Minima del Neoliberalismo. El Colegio de México/Turner.

Fukuyama, F. (2000). The great disruption: buman nature and the reconstitution of social order. Touchstone.

Hawkins, S. (2014). La inteligencia artificial podría significar el fin de la raza humana. $A b c$. Recuperado de: $\quad$ http://www.abc.es/tecnologia/informatica-software/20141202/abci-stephen-hawkingpeligros-inteligencia-201412021837.html

La Vanguardia (2014, 15 de enero). Crece la «infobesidad» en España. Recuperado de: http:/ / wmw.lavanguardia.com/tecnologia/ internet/20140115/54399158027/crece-infobesidad-espana.btml

UOC News (2013). Las redes sociales pueden tener efectos negativos en la vida en pareja. Recuperado de: $\quad$ http://www.uoc.edu/portal/es/uoc-news/actualitat/2013/noticia 147/xarxes-socialsdivorcis.html

Lorenz, K. (1995). La otra cara del espejo. Plaza \& Janés.

Mattelart, A. (1998). La mundialización de la comunicación. Barcelona: Paidós.

Otero Castelló, M. ${ }^{a}$ D. (2002). A propósito de la telefonía móvil. Una reflexión desde la perspectiva de la psicología individual y social. Revista Latina de Comunicación Social, 47. Recuperado de: http://www.ull.es/publicaciones/latina/2002/latina47febrero/4705otero.htm

Peirano, M. (2015). ¿Por qué me vigilan, si no soy nadie?, Recuperado de: https://www.youtube.com/watch?v=NPE7i8wuupk

Pérez-Lanzac, C. (2013). Mucho Facebook, ¿poca concentración? El País, 10/11/13, Recuperado de: http://sociedad.elpais.com/sociedad/2013/11/10/actualidad/1384115247 184450.html.

Popper, K. R. (2008). La lógica de la investigación cientifica. Tecnos.

Prensa Libre (2016, 24 de febrero). ¿Cómo funciona el cerebro de los nativos digitales? Recuperado de: http://www.prensalibre.com/internacional/como-funciona-el-cerebro-de-los-nativos-digitales

Ramonet, I. (1998). La tiranía de la comunicación. Madrid: Debate.

Reig, R. (2015). Crisis del sistema, crisis del periodismo. Barcelona: Gedisa.

Reig, R. (2011). Los dueños del periodismo. Claves de la estructura mediática mundial y de España. Barcelona: Gedisa.

Reig, R. (2010). La telaraña mediática. Cómo conocerla, cómo comprenderla. Sevilla: Comunicación Social Ediciones y Publicaciones.

Reig, R. (2001). El éxtasis cibernético. Madrid: Libertarias/Prodhufi.

Reig, R. (Dir.) y Mancinas-Chávez, R. (Coord.) (2013). Educación para el mercado. Barcelona: Gedisa.

Sánchez, J. M. (2014, 11 de noviembre). WhatsApp y las aplicaciones: la innovación topa contra la adicción. ABC. Recuperado de: http://www.abc.es/tecnologia/moviles/20141023/abciwhatsapp-adiccion-smartphones-tareas-ocio-entretenimiento-psicologia-201410231409.html. 
Sans, J. (1763). El sabio ignorante. Barcelona: Imprenta Teresa Piferrer. Recuperado de: https://books.google.es/books?id=QcCFK0wzbhkC\&pg=PP18\&lpg=PP18\&dq $=\mathrm{el}+\mathrm{sabio}+\mathrm{ign}$ orante\&source $=$ bl\&ots $=\mathrm{z} 4 \mathrm{Ducm} 1 \mathrm{aV} 7 \&$ sig $=5 \mathrm{iQa} 9 \mathrm{q} 2 \mathrm{Gdi}-$

Rpbkvv3rE6N8qwtc\&hl=es\&sa=X\&ved=0ahUKEwjRuvWotO7PAhWHthoKHYOwAm4Q6 AEIVjAM $\#_{\mathrm{v}}=$ onepage $\& \mathrm{q}=\mathrm{el} \% 20$ sabio $^{2} \% 20$ ignorante $\& \mathrm{f}=$ false

Serres, M. (2014). Pulgarcita. Barcelona: Gedisa.

Torres Fernández, D. y Pérez Sánchez, R. (2013). Predictores psicosociales de la satisfacción percibida con las relaciones interpersonales en el uso de la mensajería instantánea. Global Media Journal México, 10(20). Recuperado de: https://journals.tdl.org/gmjei/index.php/GMJ EI/article/view/179

Valdés Gázquez, M. (2006). El pensamiento antropológico de Franz Boas. Universidad Autónoma de Barcelona.

Van Dijk, T. A. (1999). El análisis crítico del discurso. Anthropos, 186, 23-36. Recuperado de: http://www.discursos.org/oldarticles/El $\% 20 \mathrm{an} \%$ E1lisis $\% 20 \mathrm{cr} \%$ EDtico $\% 20 \mathrm{del} \% 20$ discurso.pd f

Wilson, E. (2014). The Meaning of Human Existence. Liveright Publishing Corporation/ W.W. Norton \& Company.

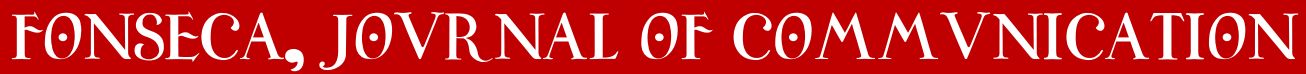

